\title{
The Impact of Attachment Style on the Family Drawings of School-Aged Children
}

\author{
Rossella Procaccia $^{1}$, Guido Veronese $^{2, *}$ and Marco Castiglioni ${ }^{2}$ \\ ${ }^{1}$ Faculty of Psychology, Università degli studi E-Campus, via Isimbardi 10, 22060, Novedrate, Italy \\ ${ }^{2}$ Department of Human Sciences "R. Massa”, University of Milano-Bicocca, Piazza dell' Ateneo Nuovo 1, 20126, \\ Milano, Italy
}

\begin{abstract}
Objectives: Primary school children's representations of themselves and their attachment figures were explored by assessing their family drawings. The main aim of the study was to empirically explore differences in the representations of children with secure versus insecure attachment. The study was theoretically informed by attachment theory and methodologically based on widely-used systems for analysing children's drawings.

Method: The Separation Anxiety Test was used to evaluate the attachment styles of 117 children (aged 6-10 years). This led to the identification of three groups, similar in age and gender distribution, with three different attachment styles (secure, anxious-ambivalent and avoidant). Each participant was asked to draw a family and the drawings produced were coded on 8 global scales and evaluated for the presence of 35 specific markers divided into five categories (characteristics of the figures; use of space; completeness of representation; emotional-affective tone; overall characteristics of the representation).

Results: The drawings of securely attached children featured more positive markers, associated with a stable and wellintegrated sense of self and others, whereas insecure children produced more markers of instability and negative emotion, with some interesting differences between anxious-ambivalent and avoidant attachment styles.

Conclusion: Despite its limitations, the study confirmed that family drawings are a valid instrument for evaluating how children represent attachment, thereby facilitating early intervention to prevent later adjustment difficulties.
\end{abstract}

Keywords: Attachment style, family drawings, representation of self and others, school-aged children.

\section{INTRODUCTION}

Drawing is widely acknowledged within clinical and developmental psychology to be an effective instrument for assessing children's cognitive, affective and emotional characteristics [1]. Children naturally tend to use drawing as a medium for expressing themselves and communicating in a non-threatening way [2], particularly when undergoing increased stress and verbal communication could be problematic [3-7]. The fact that drawing bypasses verbal channels of expression allows children to represent nonconscious elements of their mental models that they might find challenging to communicate in words [8]. Drawings are also relatively simple to administer and collect [2], thus providing rapid access to the child's inner world.

In particular, there is a well-established tradition of using family drawing in clinical practice because it offers a representation of children's perspectives on the overall dynamics in their family and on their own position in the family group $[9,10]$.

*Address correspondence to this author at the Department of Human Sciences, University of Milano-Bicocca, Piazza dell' Ateneo, Nuovo 1, 20126, Milano, Italy; Tel: +39(0)264484800; Fax: +39(0)264484863;

E-mail: guido.veronese@unimib.it
Family drawings are generally adopted on clinical and theoretical grounds, but as yet there is not a solid empirical basis for their use, despite the numerous attempts in this direction reported in the literature [9, 11-13]. Furthermore, much of the empirical work on projective drawings has relied on case studies, with little scope for generalizing from the results.

One area in which family drawings have been applied is the evaluation of children's representations of attachment $[10,14-18]$. According to attachment theory $[19,20]$ from the earliest stages of development, the input received from the family environment is organized into regular and predictable patterns underpinning the development of two distinct but complementary processes that become increasingly complex as the child grows older: selfperception and perception of the world [21, 22].

Attachment theory suggests that there is a strong connection between the mental health of individuals, and attachment relationships that made them feel emotionally supported, comforted and protected [23]. Early experiences with caregivers influence the representational models that later orient children's behaviour in novel circumstances $[19,24]$. Thus, the responsiveness displayed by caregivers 
determines the development of the so-called secure, insecure-anxious-ambivalent, insecure-avoidant or disorganized styles of attachment [20, 24, 25]. Children whose carers respond promptly and sensitively to them will display secure attachment, reflected in a tendency to have confidence in other people, perceive close relationships as comforting, and deploy effective strategies for handling stress [10]. In contrast, avoidant attachment involves a tendency to sheer away from close relationships in favour of more self-reliant modes of behaviour, while a child with anxious-ambivalent attachment craves close forms of relating to others and worries constantly that its carers may cease to be available [26].

Children with disorganized attachment display inconsistency and poor organization in their strategies for managing stress. Disorganized conduct may vary from individual to individual, but typically includes manifestations of anxiety, helplessness or depression; abrupt fluctuations between approaching and avoiding attachment figures; and other conflictual and unpredictable behaviours [27].

More recently, sound psychometric evidence has been reported in the child development literature suggesting that drawing characteristics act as valid early markers of insecure attachment. It is important for insecure attachment to be detected at as young an age as possible, given that early intervention may reduce the risk of aggressive behaviour, alienation, depressive symptoms and conduct disturbances correlated with this attachment style [10, 23, 28-32].

An early key study analysing the impact of attachment style on family drawings was conducted by Kaplan and Main [16]. Evaluating children's drawings for the presence of specific markers and for overall configuration, they found that securely attached children produced realistic representations with figures that were complete, grounded, and individuated (each family member displayed some distinctive feature), with family members placed close to one another and appearing to be happy.

Children displaying avoidant attachment produced drawings in which the figures either did not have arms or the arms were drawn in a way that was not conducive to holding, there was little individuation of family members and the overall picture was quite static. Drawings by children with ambivalent attachment featured figures that were over- or under-sized, overlapping or divided from one another. Soft body parts and facial features tended to be over-emphasized. Finally, the drawings of children with disorganized/ disoriented attachment patterns contained bizarre signs, threatening and/or fantasy themes, incomplete objects or people, or came across as excessively and irrationally sweet.

Extending the coding system of Kaplan and Main [16], Fury, Carlson and Sroufe [8] approached children's family drawings from a global perspective, coming up with a system for evaluating the overall drawing rather than individual features. The eight rating scales they devised comprised two positive dimensions (vitality/creativity and family pride/happiness) and six negative dimensions (vulnerability, emotional distance/isolation, tension/anger, role reversal, bizarreness/dissociation, and global pathology).
They explored the correlations between children's scores on these global rating scales and their attachment patterns as evaluated when they were infants, finding that even when IQ, current life stress and emotional functioning were taken into account, early attachment representations predicted the negative dimensions of children's drawings. In another study [17], children whose family drawings communicated greater emotional distance, vulnerability, and role reversal between parent and child, tended to have a record of insecure attachment, while family drawings expressing greater family pride and less pathology were produced by children who had been secure attached at an early age. Furthermore, in a longitudinal study by Carlson, Sroufe, and Egeland [33], children's family drawings at 8 years were correlated with their attachment patterns as described in interview data gathered when they were at preschool and again at age 12 years.

Following in this line of enquiry, our work builds on previous research by exploring how children's attachment is related to their family drawings, with the main aim of empirically investigating differences in the representations of securely vs. insecurely (anxious-ambivalent and avoidant) attached children.

\section{METHODS}

\subsection{Participants}

The research participants were 117 children, 58 boys $(49.6 \%)$ and 59 girls $(50.4 \%)$, aged between 6 and 10 years (mean age $=8.96$ years, $s d=1.31$ ), all from middle class socioeconomic backgrounds.

Recruited at state-run primary schools in the city of Milan and surrounding area , they were selected on the basis of their attachment style as assessed via the Separation Anxiety Test $[34,35]$ in order to obtain three groups of 39 children with "secure", "anxious-ambivalent insecure" and "avoidant insecure" attachment, respectively. Only 10 of the children initially assessed were found to display "disorganized" attachment, a number too small to be included for the purposes of the current study. The three attachment style groups were found to be adequately homogeneous in relation to gender $\left(\chi^{2}=4.582 ; \mathrm{df}=2 ; \mathrm{p}=.101\right)$ or age $(\mathrm{F}=.251 ; \mathrm{p}=.779)$ distribution.

With regard to family composition, $96.6 \%$ (n. 113) of the children lived with both their parents, while $3.4 \%$ (n. 4) lived with their mother but regularly spent time with their father. Sixteen participants (representing $13.7 \%$ of the sample) were only children, while $101(86.3 \%)$ had siblings.

\subsection{Instruments and Procedure}

Two instruments were used to pursue the research aims:

1 This study respected the Guidelines issued by the Ethics Committee at the University of Milano-Bicocca and was accorded the approval of the Ethics Committee of MIUR (Italian Ministry of Education, University and Research). Written parental informed consent was obtained. The children were also informed that participation in the research was voluntary, and that they were free to withdraw at any time, or decline to answer a particular question. 
a) The Separation Anxiety Test (SAT) [34, 35] was administered in order to assess the children's mental representation of attachment style. This instrument evaluates reactions to hypothetical scenarios of children undergoing separation from their parents, as portrayed in a set of six digital drawings in which the protagonist is of the same gender as the respondent. Three of the depicted separations are long ("severe"), and three of short duration ("moderate"). The researcher first presents and describes each picture, and then asks the participant four questions: "How do you think the child in the picture feels?"; "Why do you think he/she feels like this?"; "What do you think the child will do now?"; "What will the child do when he/she sees his/her mother (or parents) again?" By coding the children's responses, the following attachment types may be identified: secure; anxious-ambivalent; anxious-avoidant; disorganized/confused.

The SAT was individually administered to participants in a quiet area of the school building, with individual sessions lasting around 20 minutes.

b) Children's representations of self and family ties were assessed via the Family Drawing Test [36]. In the context of a group session conducted in the classroom, participants were asked to produce a family drawing, receiving the instruction "Draw a family"; this wording is designed both to stimulate participants' projective abilities and to avoid setting off potential defensive reactions. All participants were supplied with the same materials (pencil, eraser, coloured pencils) and allowed the same length of time (45 minutes) to complete the task.

\subsection{Data Analysis}

Coding was conducted by two independent judges, with a third judge intervening to resolve cases of disagreement, both for SAT (agreement $=88 \%$ ) and for family drawings (agreement $=87 \%$ ).

Two different levels of coding were applied to the participants' drawings.

At a first level of analysis, the graphic, formal and content aspects of the drawings were separately evaluated using an adapted version of the classification system developed by Kaplan and Main [16]. Specifically we devised an ad hoc coding grid comprising 35 nominally scored items grouped into five categories (Table 1).

At a second level of analysis, the drawings were evaluated using eight 5-point global rating scales, following

Table 1. Coding categories for family drawings (adapted from Kaplan \& Main, 1986).

\begin{tabular}{|c|c|c|}
\hline Characteristics of the figures & $\begin{array}{l}\text { 1) } \\
\text { 2) } \\
\text { 3) } \\
\text { 4) } \\
\text { 5) } \\
\text { 6) } \\
\text { 7) } \\
\text { 8) } \\
\text { 9) } \\
\text { 10) } \\
\text { 11) } \\
\text { 12) }\end{array}$ & $\begin{array}{l}\text { Individuation of the figures } \\
\text { Disguised family members } \\
\text { Size of figures } \\
\text { Prominence of figures within the drawing } \\
\text { Gender differentiation } \\
\text { Feminization of the mother figure } \\
\text { Figures in positions that are not conducive to hugging/holding } \\
\text { Arms downwards, close to body } \\
\text { Well-proportioned heads } \\
\text { Overall proportioning } \\
\text { Disproportionately sized body parts } \\
\text { Quality of trace (light, heavily scored etc.) }\end{array}$ \\
\hline Use of space & $\begin{array}{l}\text { 13) } \\
\text { 14) } \\
15) \\
\text { 16) } \\
\text { 17) }\end{array}$ & $\begin{array}{l}\text { Distance between figures } \\
\text { Distance between mother and child } \\
\text { Compartmentalizaion (presence of barriers, enclosures etc. dividing the figures) } \\
\text { Layout of drawing } \\
\text { Position of figures }\end{array}$ \\
\hline Completeness of representation & $\begin{array}{l}\text { 18) } \\
\text { 19) } \\
\text { 20) } \\
\text { 21) } \\
\text { 22) } \\
23) \\
24) \\
25) \\
26)\end{array}$ & $\begin{array}{l}\text { Completeness of family unit } \\
\text { Omission of figures } \\
\text { Completeness of human figure } \\
\text { Types of body part omitted } \\
\text { Contextualization } \\
\text { Line at bottom (ground) } \\
\text { Detail } \\
\text { Colour } \\
\text { Drawing incomplete }\end{array}$ \\
\hline Emotional-affective tone & $\begin{array}{l}\text { 27) } \\
28) \\
29) \\
30)\end{array}$ & $\begin{array}{l}\text { Presence of emotion expression } \\
\text { Expression of positive emotion } \\
\text { Expression of negative emotion } \\
\text { Expression of anger }\end{array}$ \\
\hline Overall characteristics of the representation & $\begin{array}{l}\text { 31) } \\
\text { 32) } \\
\text { 33) } \\
\text { 34) } \\
\text { 35) }\end{array}$ & $\begin{array}{l}\text { Bizarre signs/contents } \\
\text { Fantasy figures } \\
\text { Creativity } \\
\text { Degree of care taken with the drawing } \\
\text { Degree of organization of the drawing }\end{array}$ \\
\hline
\end{tabular}


Table 2. Family drawing global rating scales (adapted from Fury, Carslon \& Sroufe 1997).

\begin{tabular}{|l|l|}
\hline Scale & \multicolumn{1}{|c|}{ Description } \\
\hline \hline Vitality/Creativity & Emotional investment in drawing reflected in embellishment, detail, creativity \\
\hline Family Pride/Happiness & Child's sense of belonging to and happy in the family group \\
\hline Vulnerability & Vulnerability and uncertainty reflected in size distortions, placement of figures on the page, exaggeration of body parts \\
\hline Emotional Distance/Isolation & Loneliness reflected in disguised expressions of anger, neutral or negative affect, distance between mother and child \\
\hline Tension/Anger & $\begin{array}{l}\text { Tension or anger reflected in figures that appear constricted, closed, without color or detail, careless in appearance, or } \\
\text { scribbled/crossed out }\end{array}$ \\
\hline Role Reversal & Suggestions of role reversal inferred from relations of size or roles of drawing figures \\
\hline Bizarreness/Dissociation & Underlying disorganization reflected in unusual signs, symbols, fantasy themes \\
\hline Global Pathology & $\begin{array}{l}\text { Overall degree of negativity reflected in global organization, completeness of figures, use of color, detail, affect, and } \\
\text { background scene }\end{array}$ \\
\hline
\end{tabular}

the method devised by Fury, Carlson, and Sroufe [8] (Table 2).

The data set was then subjected to the following statistical procedures, using SPSS software:

a) first the chi-square test was carried out to verify whether there were significant differences among the three groups (secure; anxious-ambivalent; avoidant) in terms of the specific characteristics of their drawings;

b) then an analysis of variance (ANOVA-one way) was conducted to evaluate whether and how attachment style influenced children's scores on the eight global rating scales.

\section{RESULTS}

Analysis of the graphic, formal and content-related characteristics of the drawings confirmed that there were significant differences in the family drawings produced by secure, anxious-ambivalent and avoidant children, respectively (see Table $\mathbf{3}$ ).

With regard to the category Characteristics of the Figures the three groups differed significantly in relation to the following markers: individuation of the figures $\left(\chi^{2}=13.94 ; \quad \mathrm{df}=4 ; \mathrm{p}=.007\right) ;$ disguised family members $\left(\chi^{2}=11.37 ; \mathrm{df}=4 ; \mathrm{p}=.02\right)$; size of figures $\left(\chi^{2}=22.75 ; \mathrm{df}=8\right.$; $\mathrm{p}=.004)$; gender differentiation $\left(\chi^{2}=12.48 ; \mathrm{df}=2 ; \mathrm{p}=.002\right)$; feminization of the mother figure $\left(\chi^{2}=26.46 ; \mathrm{df}=4 ; \mathrm{p}=.0001\right)$; positions inconducive to hugging $\left(\chi^{2}=6.51 ; \mathrm{df}=2 ; \mathrm{p}=.03\right)$ and arms positioned downwards and close to body $\left(\chi^{2}=12.54\right.$; $\mathrm{df}=4 ; \mathrm{p}=.01)$.

Specifically, the drawings of securely attached children, compared to the other two groups, were more likely to feature figures that were well-individuated, genderdifferentiated and of a congruent size; mother figures were depicted as feminine; almost no drawings featured figures with arms downwards or in unsuitable positions for hugging. Anxious-ambivalent and avoidant children on the other hand were more likely to draw poorly individuated and poorly gender-differentiated figures; they also tended to emphasize one figure over the rest (the mother in the case of the ambivalent, the self in the case of avoidant group); the mother figure was less likely to be feminized and more likely to be in an awkward position for hugging. Compared to the other two groups, children with an avoidant attachment style were more inclined to draw disguised figures or figures with arms in a downwards position.

With regard to the category Use of Space, the three groups differed significantly in relation to overall layout of drawing $\left(\chi^{2}=6.51 ; \mathrm{df}=2 ; \mathrm{p}=.03\right)$ and distance between figures $\left(\chi^{2}=31.66 ; \mathrm{df}=4 ; \mathrm{p}=.0001\right)$, particularly between mother and child $\left(\chi^{2}=41.08 ; \mathrm{df}=4 ; \mathrm{p}=.0001\right)$. Specifically, the figures in the drawings of secure children were placed at an appropriate distance from one another, whereas the figures drawn by anxious-ambivalent children often overlapped (especially mother and child) and those drawn by avoidant children tended to be very distant from one another. Overall, the drawings of secure children were congruously distributed over the available space, while the anxious-ambivalent and avoidant subjects tended to produce representations with a higher proportion of "empty" space. Concerning the category Completeness of the Representation, the three groups differed significantly in relation to completeness of figures $\left(\chi^{2}=8.27 ; \mathrm{df}=2 ; \mathrm{p}=.01\right)$, body parts omitted $\left(\chi^{2}=23.36\right.$; $\mathrm{df}=10 ; \mathrm{p}=.009)$ and level of detail $\left(\chi^{2}=10.88 ; \mathrm{df}=4 ; \mathrm{p}=.02\right)$. Specifically, the secure children mainly produced drawings with complete figures and a congruent level of detail. In contrast, the anxious-ambivalent group were more likely to produce incomplete human figures, most often omitting the upper or lower limbs. Both anxious-ambivalent and avoidant subjects tended to produce drawings that were less rich in detail.

With regard to the category Emotional-Affective Tone, the three groups differed significantly in relation to emotion expression $\left(\chi^{2}=8.75 ; \mathrm{df}=4 ; \mathrm{p}=.05\right)$, both positive $\left(\chi^{2}=8.77\right.$; $\mathrm{df}=4 ; \mathrm{p}=.05)$ and negative $\left(\chi^{2}=10.65 ; \quad \mathrm{df}=4 ; \mathrm{p}=.04\right)$. Specifically secure children tended to represent figures with emotion expression, particularly positive emotion. In contrast, both anxious-ambivalent and avoidant subjects were more likely to produce faces with neutral expressions; 
when the faces drawn did express an emotion, positive emotions were less frequent.

Table 3. Attachment styles and graphic, formal and content aspects of family drawings.

\begin{tabular}{|c|c|c|c|c|c|c|c|c|}
\hline Category & Specific Marker & & Secure & $\begin{array}{c}\text { Anxious- } \\
\text { ambivalent }\end{array}$ & Avoidant & $X^{2}$ & $d f$ & $\mathbf{p}$ \\
\hline \multirow{21}{*}{$\begin{array}{l}\text { Characteristics of } \\
\text { the figures }\end{array}$} & \multirow{3}{*}{$\begin{array}{l}\text { Individuation of the } \\
\text { figures }\end{array}$} & absent & $1(2.6 \%)$ & $12(30.8 \%)$ & $13(33.3 \%)$ & \multirow{3}{*}{13.94} & \multirow{3}{*}{4} & \multirow{3}{*}{0.007} \\
\hline & & present & $35(89.7 \%)$ & $26(66.7 \%)$ & $25(64.1 \%)$ & & & \\
\hline & & strongly present & $3(7.7 \%)$ & $1(2.6 \%)$ & $1(2.6 \%)$ & & & \\
\hline & \multirow{3}{*}{$\begin{array}{l}\text { Disguised family } \\
\text { members }\end{array}$} & absent & $39(100 \%)$ & $37(94.9 \%)$ & $33(84.6 \%)$ & \multirow{3}{*}{11.37} & \multirow{3}{*}{4} & \multirow{3}{*}{0.02} \\
\hline & & present & $0(0 \%)$ & $1(2.6 \%)$ & $6(15.4 \%)$ & & & \\
\hline & & strongly present & $0(0 \%)$ & $1(2.6 \%)$ & $0(0 \%)$ & & & \\
\hline & \multirow[t]{5}{*}{ Size of figures } & all members of the same size & $34(87.2 \%)$ & $18(46.2 \%)$ & $26(66.7 \%)$ & \multirow{5}{*}{22.75} & \multirow{5}{*}{8} & \multirow{5}{*}{0.004} \\
\hline & & mother & $1(2.6 \%)$ & $11(28.2 \%)$ & $5(12.8 \%)$ & & & \\
\hline & & father & $3 / 7.7 \%)$ & $7(17.9 \%)$ & $3(7.7 \%)$ & & & \\
\hline & & brother/sister & $1(2.6 \%)$ & $1(2.6 \%)$ & $0(0 \%)$ & & & \\
\hline & & self & $0(0 \%)$ & $2(5.1)$ & $5(12.8 \%)$ & & & \\
\hline & \multirow{2}{*}{$\begin{array}{c}\text { Gender } \\
\text { differentiation }\end{array}$} & absent & $2(5.1 \%)$ & $11(28.2 \%)$ & $15(38.5 \%)$ & \multirow[t]{2}{*}{12.48} & \multirow[t]{2}{*}{2} & \multirow[t]{2}{*}{0.002} \\
\hline & & present & $37(94.9 \%)$ & $28(71.8 \%)$ & $24(61.5 \%)$ & & & \\
\hline & \multirow{3}{*}{$\begin{array}{c}\text { Feminization of the } \\
\text { mother figure }\end{array}$} & absent & $1(2.6 \%)$ & $18(46.2 \%)$ & $19(48.7 \%)$ & \multirow{3}{*}{26.46} & \multirow{3}{*}{4} & \multirow{3}{*}{0.001} \\
\hline & & present & $38(97.4 \%)$ & $20(51.3 \%)$ & $20(51.3 \%)$ & & & \\
\hline & & strongly present & $0(0 \%)$ & $1(2.6 \%)$ & $0(0 \%)$ & & & \\
\hline & \multirow{2}{*}{$\begin{array}{l}\text { Figures in positions } \\
\text { that are not } \\
\text { conducive to } \\
\text { hugging/holding }\end{array}$} & absent & $36(92.3 \%)$ & $28(71.8 \%)$ & $28(71.8 \%)$ & \multirow[b]{2}{*}{6.51} & \multirow[b]{2}{*}{2} & \multirow[b]{2}{*}{0.03} \\
\hline & & present & $3(7.7 \%)$ & $11(28.2 \%)$ & $11(28.2 \%)$ & & & \\
\hline & \multirow[t]{3}{*}{ Arms downwards } & absent & $38(97.4 \%)$ & $31(79.5 \%)$ & $29(74.4 \%)$ & \multirow{3}{*}{12.54} & \multirow{3}{*}{4} & \\
\hline & & present & $1(2.6 \%)$ & $6(15.4 \%)$ & $10(25.6 \%)$ & & & 0.01 \\
\hline & & strongly present & $0(0 \%)$ & $2(5.1 \%)$ & $0(0 \%)$ & & & \\
\hline & Distance between & absent & $2(5.1 \%)$ & $17(43.6 \%)$ & $9(23.1 \%)$ & & & \\
\hline & 11gures & present & $35(89.7 \%)$ & $20(51.3 \%)$ & $18(46.2 \%)$ & 31.66 & 4 & 0.001 \\
\hline & & strongly present & $2(5.1 \%)$ & $2(5.1 \%)$ & $12(30.8 \%)$ & & & \\
\hline Use of space & Distance between & absent & $2(5.1 \%)$ & $16(41.0 \%)$ & $7(17.9 \%)$ & & & \\
\hline & mother and child & present & $33(84.6 \%)$ & $19(48.7 \%)$ & $12(30.8 \%)$ & 41.08 & 4 & 0.001 \\
\hline & & strongly present & $4(10.3 \%)$ & $4(20 \%)$ & $20(51.3 \%)$ & & & \\
\hline & Layout of drawing & Balanced distribution & $30(76.9 \%)$ & $17(43.6 \%)$ & $19(48.7 \%)$ & & & \\
\hline & & "empty" drawing & $2(5.1 \%)$ & $14(35.9 \%)$ & $15(38.5 \%)$ & 15.28 & 4 & 0.004 \\
\hline & & "full" drawing & $7(17.9 \%)$ & $8(20.5 \%)$ & $5(12.8 \%)$ & & & \\
\hline Co & Completeness of & complete & $37(94.9 \%)$ & $28(71.8 \%)$ & $34(87.2 \%)$ & & & \\
\hline representation & human figure & incomplete & $2(5.1 \%)$ & $11(28.2 \%)$ & $5(12.8 \%)$ & 8.27 & 2 & 0.01 \\
\hline
\end{tabular}


Table 3. Contd.....

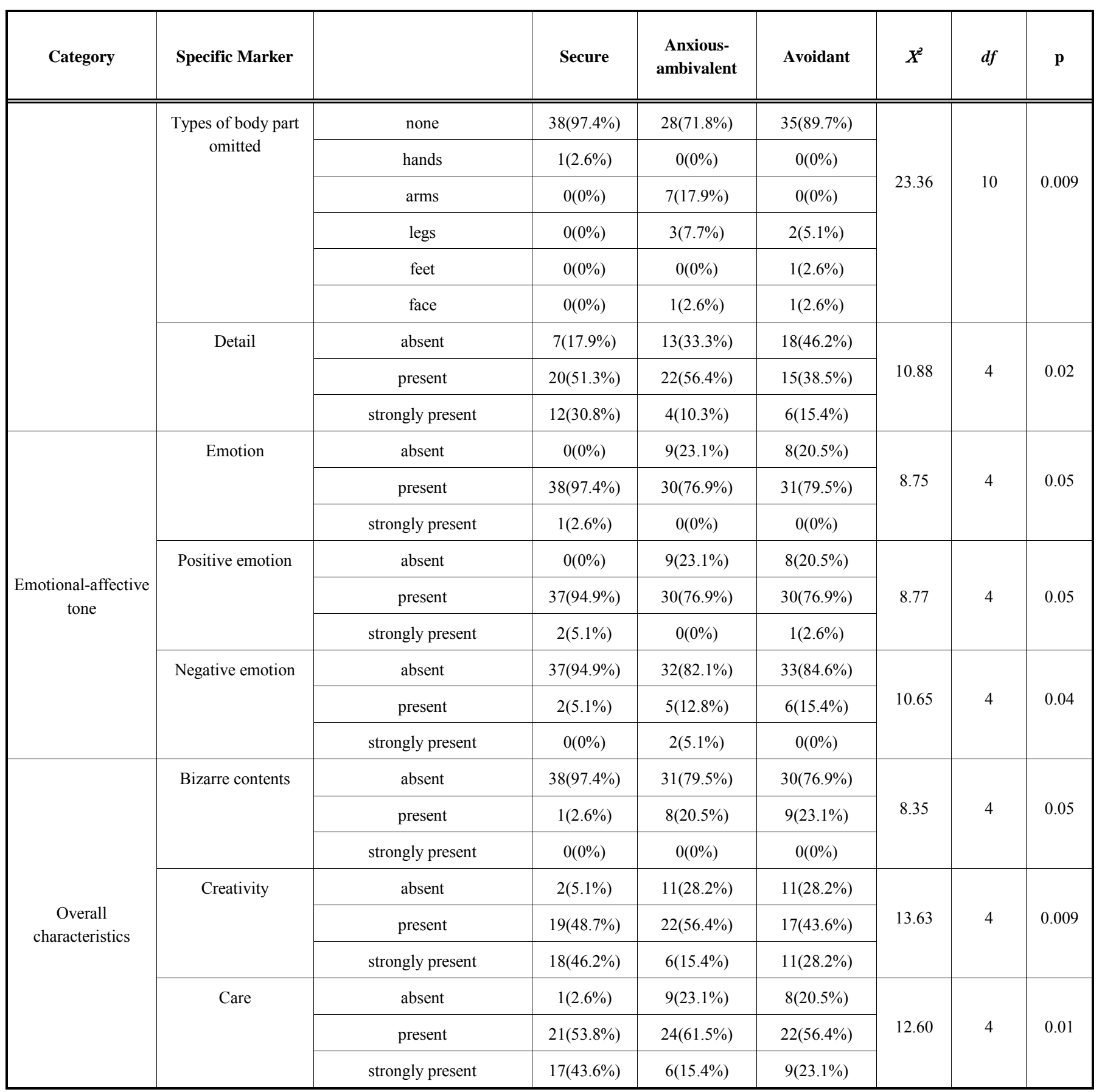

Concerning the final category of analysis, Overall Characteristics of the Representation, the three groups differed significantly in relation to: bizarre contents $\left(\chi^{2}=8.35 ; \mathrm{df}=4 ; \mathrm{p}=.05\right)$, creativity $\left(\chi^{2}=13.63 ; \mathrm{df}=4 ; \mathrm{p}=.009\right)$ and care taken with the drawing $\left(\chi^{2}=12.60 ; \mathrm{df}=4 ; \mathrm{p}=.01\right)$.

Specifically the drawings of insecure children (both anxious-ambivalent and avoidant) were more likely to contain bizarre contents (unrecognizable objects, objects floating in the sky, etc.); they also displayed less creativity and seemed to have had less care taken over them than those of the secure group.

The results of the ANOVA show that the three groups differed significantly in relation to all of the global rating scales (see Table 4).

Specifically, the secure children obtained higher scores than the other two groups on Vitality $(\mathrm{F}=33.98 ; \mathrm{p}=0.001)$ and Pride/Happiness $(\mathrm{F}=40.15 ; \mathrm{p}=0.0001)$ and lower scores on Vulnerability $(\mathrm{F}=21.62 ; \mathrm{p}=0.0001)$, Emotional Distance 
Table 4. Attachment styles and Global rating scales.

\begin{tabular}{|c|c|c|c|c|c|}
\hline & Secure & Anxious - ambivalent & Avoidant & & \\
\hline Global scales & Mean $(S D)$ & Mean $(S D)$ & Mean $(S D)$ & $\mathrm{F}$ & $\mathrm{p}$ \\
\hline Vitality/Creativity & $4.38(0.87)$ & $2.54(1.02)$ & $3.05(1.14)$ & 33.982 & 0.001 \\
\hline Family Pride/Happiness & $3.64(1.78)$ & $1.28(1.02)$ & $1.31(1.05)$ & 40.153 & 0.001 \\
\hline Vulnerability & $1.36(0.34)$ & $3.03(1.46)$ & $3.10(1.14)$ & 21.627 & 0.001 \\
\hline Emotional Distance/Isolation & $1.08(0.58)$ & $2.31(1.39)$ & $3.72(1.33)$ & 34.514 & 0.001 \\
\hline Tension/Anger & $0.90(0.54)$ & $2.10(1.53)$ & $1.97(1.59)$ & 6.200 & 0.003 \\
\hline Role Reversal & $0.77(0.13)$ & $1.69(1.12)$ & $1.23(1.21)$ & 2.478 & 0.088 \\
\hline Bizarreness/Dissociation & $0(0)$ & $1.15(0.50)$ & $0.54(1.12)$ & 10.237 & 0.001 \\
\hline Global Pathology & $0.67(0.15)$ & $3.82(1.03)$ & $2.97(1.24)$ & 81.489 & 0.001 \\
\hline
\end{tabular}

$(\mathrm{F}=34.51 ; \mathrm{p}=0.001)$, Anger $(\mathrm{F}=6.20 ; \mathrm{p}=0.003)$, Bizarreness/ Dissociation $(\mathrm{F}=10.23 ; \mathrm{p}=0.001)$ and Global Pathology $(\mathrm{F}=81.48 ; \mathrm{p}=0.001)$. On the Role Reversal Scale $(F=2.47 ; p=0.02)$ the secure children obtained lower scores than the anxious-ambivalent group only.

Significant differences were also found between the two different styles of insecure attachment. Specifically the anxious-ambivalent group scored higher than the avoidant group on Bizarreness/Dissociation $(\mathrm{F}=10.23$; $\mathrm{p}=0.001)$ and Global Pathology $(F=81.48 ; p=0.0001)$. The avoidant group on the other hand scored higher than either of the other two groups on Emotional Distance $(F=34.51 ; p=0.001)$ and higher than the anxious-ambivalent group on Vitality $(\mathrm{F}=33.98 ; \mathrm{p}=0.001)$.

\section{DISCUSSION}

On the whole, the results of this study imply that children's drawings are a strong measure that may be used to access children's representations of attachment. Family drawings especially may be an effective instrument for exploring the more subjective, personal, and possibly unconscious aspects of representational models of the self in relationships. In line with other findings reported in the literature $[8,16]$ our data confirms that there are significant differences in the family drawings of securely versus insecurely attached children, both with regard to specific markers (graphic, formal and content-related) and with regard to the overall drawing. From our analysis it emerged that the drawings of securely attached children featured figures that were clearly individuated in terms of gender and age, denoting a stable and positive sense of self and good ability to differentiate between self and other. These children also displayed satisfactory integration of the bodily with the psychic self: figures were well-proportioned and no body parts were omitted. There were also markers of a sense of trust in others and an internalized model of parent figures that was both stable and positive: no family members were omitted from the drawings and none were represented in positions unsuitable for hugging and holding. A balanced use was made of space and family members were placed at a natural distance from one another, implying the capacity to perceive the other as close to the self but not to the detriment of personal identity or space. All these features seem to be coherent with the experience of an attachment figure capable of meeting the child's needs, particularly in terms of providing comfort and reassurance at times of stress and a secure base from which to explore the external world [37]. These children appear to have attained a balanced position along the individuality-otherness continuum that reconciles the need for self-realization with the need for belonging/affiliation. They also seem to be competent in expressing the emotional components of their relationships, mainly characterized by positive affect.

In contrast, the drawings of children with anxiousambivalent attachment styles were characterized by poor individuation of figures, little differentiation on the basis of gender and age, with a tendency to emphasize the mother figure and to eliminate the distance between mother and child. The figures were frequently incomplete, in awkward positions for hugging or holding, poor in detail and displaying either lack of emotion or negative emotion. It may be argued that early experiences of intermittent or unreliable response on the part of caregivers [37] has brought about an unstable and confused sense of self and others and that it is difficult for anxious-ambivalent children to find the "right" distance from others, leading them to alternate sometimes excessive attempts to draw close to others, with moments of rejection and separation on the other, a challenge that is clearly graphically represented in the drawings. Similarly, the drawings of children with an avoidant attachment style contained markers denoting difficulty in attaining a stable and positive sense of self and others (poor individuation, poor differentiation, etc.), for which these children defensively compensate by investing in self image, overindependence and denial of emotions. The presence of disguised figures, figures in positions that are not conducive to hugging or with their arms at their sides, figures without emotional expression or only expressing negative emotion, figures with little detail or positioned far away from one another, all imply that this group of children view the self as an unlovable subject who only has itself to rely on, while viewing others as rejecting, hostile and unresponsive [37]. Integrative assessment via the eight Global Scales proved to 
be even more sensitive than analysis of specific markers in detecting differences between children with different representations of attachment. As shown in previous research $[8,17]$, the drawings of securely attached children received the highest scores on positive dimensions (vitality and pride) and the lowest on dimensions reflecting possible difficulties in adjustment. The ambivalently attached children were more inclined to represent role reversal than were children with secure attachment; the drawings of ambivalently attached children also displayed greater bizarreness/dissociation and global pathology, all potentially associated with other forms of maladjustment. The avoidant group expressed greater emotional distance and isolation than the ambivalent group, possibly denoting feelings of loneliness and poor support from caregivers. Similar results emerged from another study of our own with primary school children [38], in which we explored the relationship between attachment style and children's written self-other narratives as assessed using selfcharacterization analysis [39].

Finally, some methodological comment is required regarding the limitations of this study and its possible further developments. First, the relatively limited size of our sample, especially considering the broad age range considered, and the homogeneous cultural background of the subjects (all Italian), does not allow us to generalize from our findings. Second, when using drawings to access representational models, the research might be enriched by efforts to examine children's affective and behavioural responses during the drawing task itself. From both a methodological and clinical perspective, another promising future line of enquiry - that could yield interesting data also in relation to children regards the cross-comparison between drawings and narrative techniques. In particular, it could be of great interest to investigate how children's self-characterizations correlate with their drawings $[38,40]$, a line of research that we intend to pursue in the near future. In addition, it would be interesting to extend this line of enquiry to clinical samples, including subjects with disorganized attachment (a pattern that is more frequently correlated with psychopathological symptoms), traumatized or abused subjects [7, 41, 42] and adolescents and young adults suffering from different disorders [43-47], in a multicultural perspective [48-50]. This would mean that family drawing could also play a key role in diagnosing and treating psychological distress during development. Finally, exploring children's drawings systematically and in depth may contribute to refining future intervention strategies, encouraging clinicians to work with children's individual strengths as well as on their individual challenges.

\section{CONFLICT OF INTEREST}

The authors have no conflict of interest to declare in relation to the content of this article.

\section{ACKNOWLEDGEMENTS}

Declared none.

\section{REFERENCES}

[1] Thomas GV, Silk AMJ, Eds. Psychology of children's drawings. Bologna: Il Mulino 1998.

[2] Malchiodi CA, Ed. Understanding children's drawings. New York: Guilford Press 1998.

[3] Klorer PG, Chapman L, Eds. Cumulative trauma and art therapy: Neurodevelopmental advances in theory and practice. Presentation at the American Art Therapy Association, Inc. 35th Annual Conference; 2004 Nov 10-14; San Diego, California 2004.

[4] Van de Kolk BA. Post-traumatic therapy in the age of neuroscience. Psychoanal Dialogues 2002; 12(3): 381-92.

[5] Ionio C, Procaccia R. Traumatic communication: sexually abused children's drawings. Maltrattamento e Abuso all'Infanzia 2003; 5(2): 57-85.

[6] Ionio C, Procaccia R. Family drawings in sexually abused children. Maltrattamento e Abuso all'Infanzia 2006; 8(2): 91-109.

[7] Veronese G, Procaccia R, Makmoud S, Castiglioni M. Draw the war: effects of extreme trauma in Palestinian children in West Bank. Psicologia clinica dello sviluppo 2010; 14(1): 219-28.

[8] Fury G, Carlson E, Sroufe A. Children's representations of attachment relationships in family drawing. Child Dev 1997; 68(6): 1154-64.

[9] Leon K, Wallace T, Rudy D. Representations of parent-child alliances in children's family drawings. Soc Dev 2007; 16: 440-59.

[10] Goldner L, Scharf M. Children's family drawings: a study of attachment, personality, and adjustment. J Am Art Ther Assoc 2011; 28(1): 11-8.

[11] Deaver SP. A normative study of children's drawings: preliminary research findings: art therapy. J Am Art Ther Assoc 2009; 26(1): 411.

[12] Milne LC, Greenway P, Best F. Children's behavior and their graphic representation of parents and self. Arts Psychother 2005; 32: $107-19$.

[13] Shiakou M. Representations of attachment patterns in the family drawings of maltreated and non-maltreated children. Child Abuse Rev 2012; 21: 203-18.

[14] Behrens KY, Kaplan N. Japanese children's family drawings and their link to attachment. Attach Hum Develop 2011; 13: 437-50.

[15] Fihrer I, McMahon C. Maternal state of mind regarding attachment, maternal depression and children's family drawings in the early school years. Attach Hum Develop 2009; 11: 537-56.

[16] Kaplan N, Main M, Eds. Instructions for the classification of children's family drawings in terms of representation of attachment. Berkeley, CA: University of California 1986.

[17] Madigan SM, Ladd M, Goldberg S. One picture is worth a thousand words: children's representations of family as indicators of early attachment. Attach Hum Develop 2003; 5: 19-37.

[18] Pianta RC, Logmaid K, Ferguson FE. Attachment based classification of children's family drawings: psychometric properties and relations with children's adjustment in kindergarten. J Clin Child Psychol 1999; 28: 144-255.

[19] Bowlby J. Attachment and loss; vol. 1: Attachment, 1969. New York: Basic Books.

[20] Bowlby, J. Attachment and loss; vol. 2. Separation, 1973. New York: Basic.

[21] Guidano VF. Complexity of the self: a developmental approach to psychopathology and therapy. New York: Guilford Press 1987.

[22] Trevarthen C, Aitken KJ. Infant intersubjectivity: research, theory and clinical application. J Child Psychol Psychiatr 2001; 42: 3-48.

[23] Goldner L, Scharf M. Children's family drawings and internalizing problems. Arts Psychother 2012; 39: 262-71.

[24] Bretherton I, Munholland KA. Internal working models in attachment relationships: elaborating a central construct in attachment theory. In: Cassidy J, Shaver PR, Eds. Handbook of attachment: Theory, research, and clinical applications. $2^{\text {nd }}$ ed. New York: Guilford 2008; pp.102-27.

[25] Ainsworth M, Blehar M, Waters E, Wall S, Eds. Patterns of attachment: a psychological study of the strange situation. Hillsdale: Erlbaum 1978.

[26] Mikulincer M, Shaver PR, Eds. Attachment in adulthood: structure, dynamics, and change. New York: Guilford Press 2006; pp. 160-3.

[27] Main M, Solomon J. Procedures for identifying infants as disorganized/disoriented during the ainsworth strange situation. In: Greenberg MT, Cicchetti D, Cummings EM, Eds. Attachment in the pre- 
school years: theory, research, and intervention. Chicago: University of Chicago Press 1990; 121-60.

[28] Belsky J, Fearon RM. Early attachment security, subsequent maternal sensitivity, and later child development: does continuity in development depend upon continuity of caregiving? Attach Hum Develop 2002; 493: 361-87.

[29] Olson SL, Bates JE, Sandy JM, Lanthier R. Early developmental precursors of externalizing behavior in middle childhood and adolescence. J Abnormal Psychol 2000; 28(2): 119-23.

[30] Sroufe AL, Carlson EA, Levy AK, Egeland B. Implications of attachment theory for developmental psychopathology. Develop Psychopathol 1999; 11: 1-13.

[31] Sroufe AL. Early relationship and the development of children. Infant Mental Health J 2000; 21(1-2): 67-74.

[32] Webster-Stratton C, Reid MJ. The incredible years parents, teachers and children training series: A multifaceted treatment approach for young children with conduct problems. In: Kazdin AE, Weisz JR, Eds. Evidence-based psychotherapies for children and adolescents. New York: The Guilford Press 2003; 224-40.

[33] Carlson EA, Sroufe LA, Egeland B. The construction of experience: a longitudinal study of representation and behavior. Child Dev 2004; 75: 66-83.

[34] Klagsbrun M, Bowlby J. Responses to separation from parents: a clinical test for young children. Proj Psychol 1976; 21: 109-26.

[35] Attili G, Ed. Separation anxiety and measurement of normal and pathological attachment. Milano: Unicopli 2001.

[36] Corman L, Ed. Family Drawing: test for children. Torino: Bollati Boringhieri 1970

[37] Bowlby J, Ed. A secure base: parent-child attachment and healthy human development. USA: Basic Books 1988.

[38] Procaccia R, Veronese G, Castiglioni M. Self-characterization and attachment style: a creative method of investigating children's construing. J Constr Psychol 2014; 27(3): 174-93, DOI: 10.1080/10720537.2014.904701

[39] Kelly GA, Ed. The psychology of personal construct. New York: Norton 1955.
[40] Bell SJ, Bell RC. An illustration of self characterization in a child's drawing: the importance of process. Pers Constr Theory Pract 2008; 5: 1-9.

[41] Di Blasio P, Miragoli S, Procaccia R. The role of PTSD in understanding child allegations of sexual abuse: post-traumatic syndromes in childhood and adolescence. A Handbook of Research and Practice 2012; 175-98.

[42] Procaccia R, Miragoli S, Di Blasio P. Blacky Pictures' Test in the evaluation of child sexual abuse. Maltrattamento e Abuso all'Infanzia 2013; 15(3): 109-30.

[43] Veronese G, Ruggiero GM, Sassaroli S, Castiglioni M. Interpersonal and individual factors in the grandiose fantasies and threats to self-esteem of a non-clinical sample. Open Psychol J 2011; 4: 1-5.

[44] Castiglioni M, Faccio E, Veronese G, Bell RC. The semantics of power among people with eating disorders. J Constr Psychol 2013; 26(1): $62-76$

[45] Castiglioni M, Pepe A, Gandino G, Veronese G. Self-other positioning in obesity: a pilot study using repertory grid technique. Open Psychol J 2013; 6(1): 61-8.

[46] Veronese G, Procaccia R, Romaioli D, Barola G, Castiglioni M. Psychopathological organizations and attachment styles in patients with fear of flying: a case study. Open Psychol J 2013; 6(1): 20-7.

[47] Castiglioni M, Veronese G, Pepe A, Villegas M. The semantics of freedom in agoraphobic patients: an empirical study. J Constr Psychol 2014; 27(2): 120-36.

[48] Veronese G, Castiglioni M, Tombolani M, Said M. My happiness is the refugee camp, my future Palestine: optimism, life satisfaction and perceived happiness in a group of Palestinian children. Scand J Caring Sci 2012; 26(3): 467-73.

[49] Veronese G, Castiglioni M, Barola G, Said M. Living in the shadow of occupation: life satisfaction and positive emotion as protective factors in a group of Palestinian school children. Child Youth Serv Rev 2012; 34(1): 225- 33

[50] Veronese G, Castiglioni M, Said M. The use of narrativeexperiential instruments in contexts of military violence: the case of Palestinian children in the West Bank. Couns Psychol Q 2010; 23(4): 411-23.

(C) Procaccia et al.; Licensee Bentham Open.

This is an open access article licensed under the terms of the Creative Commons Attribution Non-Commercial License (http://creativecommons.org/licenses/by-nc/3.0/) which permits unrestricted, non-commercial use, distribution and reproduction in any medium, provided the work is properly cited. 